\title{
A Comparative Study of the Effects of Methyl Jasmonate and Abscisic Acid on Some Rice Physiological Processes
}

\author{
C.-C. Yeh, ${ }^{1}$ H.-S. Tsay, ${ }^{1}$ J.-H. Yeh, ${ }^{2}$ F.-Y. Tsai, ${ }^{2}$ C.-Y. Shih, ${ }^{2}$ and C.-H. Kao ${ }^{2, *}$ \\ ${ }^{1}$ Department of Agronomy, Taiwan Agricultural Research Institute, Taichung, Taiwan; ${ }^{2}$ Department of Agronomy, National Taiwan \\ University, Taipei, Taiwan, Republic of China
}

Received June 27, 1994; accepted October 12, 1994

\begin{abstract}
The effects of methyl jasmonate (MJ) and abscisic acid (ABA) on some physiological processes of rice were compared. $\mathrm{MJ}$ exhibited $\mathrm{ABA}$ like effects by promoting senescence of detached leaves, by inducing acid phosphatase activity of detached leaves, by inhibiting ethylene production and shoot growth of seedlings, as well as inhibiting callus formation from anthers. However, MJ and ABA had opposite effects on 1-aminocyclopropane1-carboxylic acid-dependent ethylene production in detached leaves. The regeneration ability of antherderived callus was inhibited by $\mathrm{MJ}$ but not by $\mathrm{ABA}$. $M J$ but not ABA markedly induced peroxidase activity in senescing detached leaves. It is concluded that not all physiological processes of rice affected by $\mathrm{MJ}$ are similar to those by ABA.
\end{abstract}

Jasmonates belong to ubiquitous cyclopentanone compounds, which are classed as new types of regulators for plant growth and differentiation. In recent years interest has grown in this type of plant substance since they either inhibit or promote many physiological processes (Sembdner and Parthier 1993). Abscisic acid (ABA) is also ubiquitous in higher plants and has multiple physiologic effects on the growth and differentiation of plants (Creelman 1989). Jasmonates have both chemical and physiological similarities to ABA (Anderson et al. 1989). Recently, we demonstrated that methyl jasmonate (MJ) and ABA had opposite effects on pu-

\footnotetext{
Abbreviations: ABA, abscisic acid; MJ, methyl jasmonate; ACC, 1-aminocyclopropane-1-carboxylic acid; Apase, acid phosphatase.

* Author for correspondence.
}

trescine and proline production in excised rice leaves (Chen and Kao 1993, Chen et al. 1994). Thus it would be of great interest to compare the effects of $\mathrm{MJ}$ and $\mathrm{ABA}$ on other rice physiological processes. The physiological processes examined in the present investigation are ACC-dependent ethylene production in detached leaves, induction of Apase in detached leaves, activity of peroxidase in senescing detached leaves, growth of seedlings, induction of callus from anthers, and regeneration ability of anther-derived callus.

\section{Materials and Methods}

Two rice (Oryza sativa L.) cultivars (Taichung Native 1 and Tainung 67) were used in the present investigation. In experiments using leaf segments, rice seedlings were cultured as described previously (Kao 1980). The apical 3-cm segments excised from the third leaves of 10-day-old seedlings were used. A group of 10 segments was floated on $10 \mathrm{ml}$ of test solutions in a Petri dish. Incubation was carried out at $27^{\circ} \mathrm{C}$ in darkness or in the light $\left(16.7 \mathrm{Wm}^{-2}\right)$. ACC-dependent ethylene production was determined according to the procedures described previously (Chou and Kao 1992). For enzyme extraction, leaf segments were homogenized in a prechilled mortar and pestle with cold 50 $\mathrm{mM}$ Tris maleate buffer, $\mathrm{pH} 7.0$, containing $13 \mathrm{mM}$ mercaptoethanol at $4{ }^{\circ} \mathrm{C}$. The homogenate was centrifuged at $10,000 \times \mathrm{g}$ for $30 \mathrm{~min}$ at $4{ }^{\circ} \mathrm{C}$. The resulting clear supernatant was used directly for enzyme assay. Apase activity was assayed using p-nitrophenyl phosphate as substrate (Huang and Kao 1991). One unit of Apase activity is defined as the amount of enzyme which liberates $1 \mu \mathrm{mol}$ of $p$-nitrophenol/min. Peroxidase activity was measured using guaiacol as substrate (Hurng and Kao 1994). One unit of peroxidase activity is defined as an increase of 1 $A_{470} / \mathrm{min}$. Chlorophyll and protein were extracted and determined as described previously (Chen and Kao 1991).

For the experiments in which the effects of MJ and ABA on seedling growth were compared, rice seeds were sterilized with $2.5 \%$ sodium hypochlorite for $15 \mathrm{~min}$ and washed thoroughly with distilled water. The seeds were then germinated in a Petri 
dish containing distilled water at $37^{\circ} \mathrm{C}$ under dark conditions. After a 2-day incubation, seedlings with 2-mm shoots were used. Ten seedlings were transferred to a $30-\mathrm{ml}$ flask with $2 \mathrm{ml}$ of test solutions. The flasks were sealed with rubber serum caps and incubated at $27{ }^{\circ} \mathrm{C}$ in darkness. Shoot length and ethylene production were measured at 6 days after treatment. Ethylene was assayed as described previously (Kao and Yang 1982).

Anthers at the uninucleate stage from rice plants grown in the field were used for callus induction. The sampling and sterilization of anthers have been described thoroughly (Wen et al. 1992). Anthers were inoculated into NK medium with or without $\mathrm{MJ}$ or $\mathrm{ABA}$ at $25^{\circ} \mathrm{C}$ in darkness. NK medium contains nitrogen inorganic salts (Chu et al. 1975) and Murashige and Skoog organic substances (Murashige and Skoog 1962) supplemented with $2 \mathrm{mg} / \mathrm{L}$ kinetin, $4 \mathrm{mg} / \mathrm{L}$ naphthaleneacetic acid, $6 \%$ sucrose, and $0.9 \%$ Difco agar, $\mathrm{pH}$ 5.7. The number of anthers producing callus was recorded at 60 days after the inoculation of anthers. For regeneration experiments, 2-4-mm anther-derived calli were subcultured in NK medium containing various concentrations of $\mathrm{MJ}$ and ABA for 1 week in darkness. Calli were subsequently transferred to R-2 medium and incubated for 4 weeks at $25^{\circ} \mathrm{C}$ in the light ( $100 \mathrm{Wm}^{-2}, 16-\mathrm{h}$ day). R-2 medium contains Murashige and Skoog basic medium (Murashige and Skoog 1962) supplemented with $2 \mathrm{mg} / \mathrm{L}$ kinetin, $0.5 \mathrm{mg} / \mathrm{L}$ naphthaleneacetic acid, 40 $\mathrm{mg} / \mathrm{L}$ adenine sulfate, $3 \%$ sucrose, and $0.9 \%$ Difco agar, $\mathrm{pH} 5.7$. The regeneration ability of anther-derived callus was followed by counting the number of greening seedlings produced.

Chlorophyll and protein levels, enzyme activities, and ethylene production were expressed on the basis of fresh weight.

For all measurements, each treatment was repeated four times. All experiments described here were repeated at least three times. Similar results and identical trends were obtained each time. The data reported here are from a single experiment.

\section{Results}

\section{ACC-dependent Ethylene Production in Detached Rice Leaves}

The effects of the concentration of MJ and ABA on ACC-dependent ethylene production in detached rice leaves in darkness are presented in Figure 1. MJ markedly promoted ACC-dependent ethylene production in detached rice leaves. Increasing the MJ concentration from 0.45 to $45 \mu \mathrm{M}$ progressively enhanced ACC-dependent ethylene production by detached rice leaves. ACC-dependent ethylene production declined at a $\mathrm{MJ}$ concentration of $450 \mu \mathrm{M}$. In contrast, $\mathrm{ABA}$ at concentrations higher than 4.5 $\mu \mathrm{M}$ significantly inhibited ACC-dependent ethylene production.

\section{Induction of Apase Activity in Detached Rice Leaves}

Detached rice leaves treated with MJ for $24 \mathrm{~h}$ in the light showed a marked increase in Apase activity (Fig. 2). MJ at a concentration of $11.25 \mu \mathrm{M}$ resulted in a maximum activity of Apase, about four times

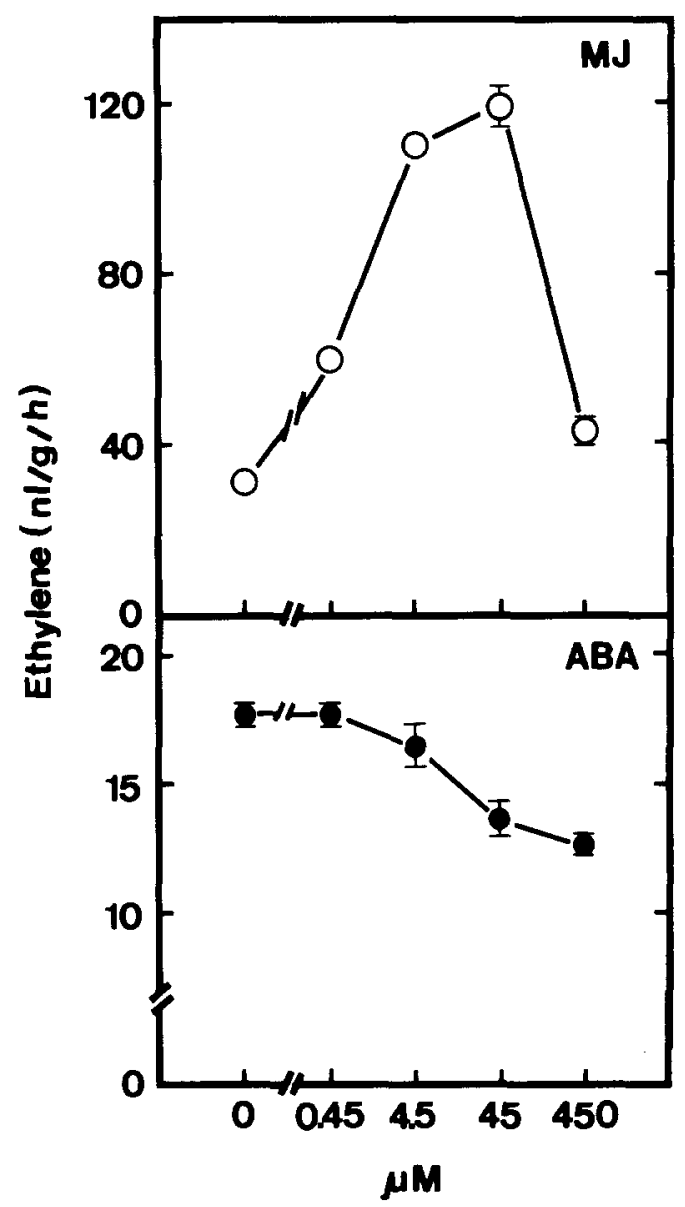

Fig. 1. Effects of MJ and ABA concentrations on ACC-dependent ethylene production in detached rice leaves (cv. Taichung Native 1). Detached rice leaves were pretreated with $10 \mathrm{mM}$ ACC in water for $2 \mathrm{~h}$ and then treated with various concentrations of $\mathrm{MJ}$ and $\mathrm{ABA}$ in darkness. Ethylene production was assayed after $6 \mathrm{~h}$ of treatment. Bars indicate standard errors $(n=4)$.

that of the water control. However, ABA caused only a $50 \%$ increase Apase activity at $67.5 \mu \mathrm{M}$.

\section{Senescence of Detached Rice Leaves}

The senescence of detached rice leaves (cv. Tainung 67) was followed by measuring the decrease of chlorophyll and protein. ABA $(45 \mu \mathrm{M})$ significantly promoted dark-induced senescence of detached rice leaves (Fig. 3). MJ (45 $\mu \mathrm{M})$ showed a similar pattern for chlorophyll loss but was slightly weaker than ABA in reducing protein content (Fig. 4). ABA had no effect on peroxidase activity in detached rice leaves during senescence, but MJ markedly promoted peroxidase activity (Figs. 3 and 4). Similar results were obtained when detached rice 


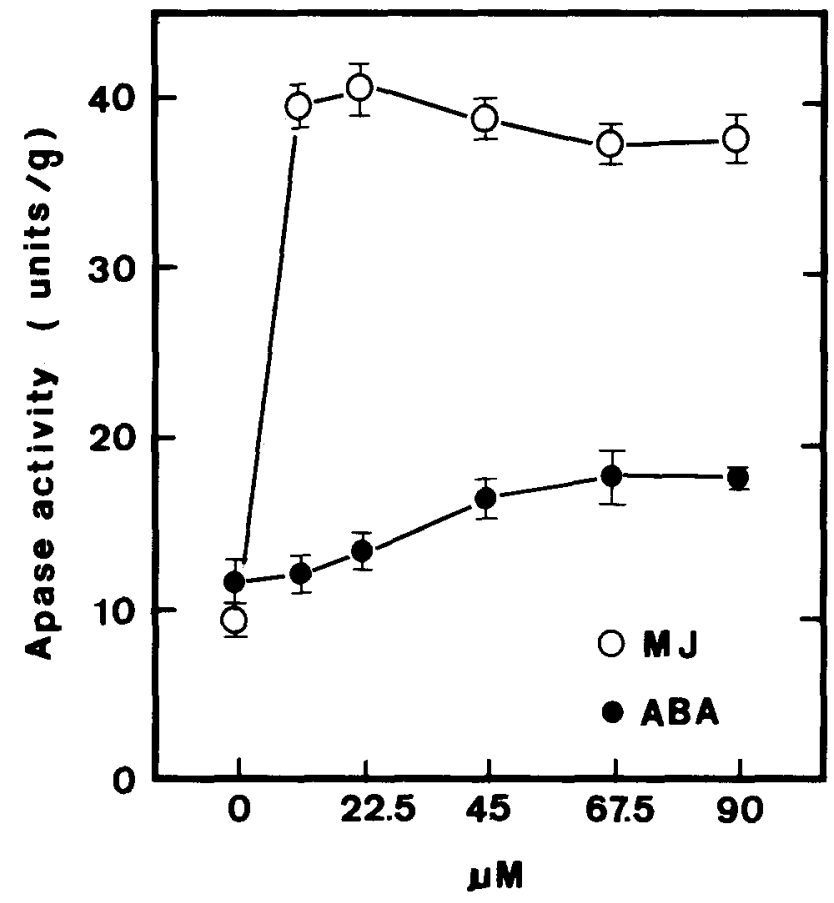

Fig. 2. Effects of MJ and ABA concentrations on Apase activity in detached rice leaves (cv. Taichung Native 1). Detached rice leaves were treated with various concentrations of MJ and ABA in the light. Apase was extracted and assayed after $24 \mathrm{~h}$ of treatment. Bars indicate standard errors $(n=4)$.

leaves of cultivar Taichung Native 1 were used (Yeh and Kao 1994).

\section{Seedling Growth}

Figure 5 shows the effects of the concentration of $\mathrm{MJ}$ and ABA on shoot growth of etiolated rice seedlings. Both $\mathrm{MJ}$ and ABA significantly inhibited shoot growth. Increasing the $\mathrm{MJ}$ concentration from 0.45 to $45 \mu \mathrm{M}$ progressively inhibited shoot growth. However, ABA-inhibited shoot growth was observed only when the concentration was $4.5 \mu \mathrm{M}$ or higher. At the highest concentration $(45 \mu \mathrm{M})$, ABA was observed to be more effective in inhibiting shoot growth than MJ. Neither MJ nor ABA inhibited the growth of roots or coleoptile (data not shown). Rice seedlings survive under oxygenrestricted environments such as hypoxia and submergence (Raskin and Kende 1983, Turner et al. 1981). It has been established that ethylene is an important factor in the stimulation of rice coleoptile growth (Ku et al. 1970). It is not known whether ethylene also regulates rice shoot growth. Thus we also determined the effects of MJ and ABA on ethylene production of rice seedlings (Fig. 5). ABA

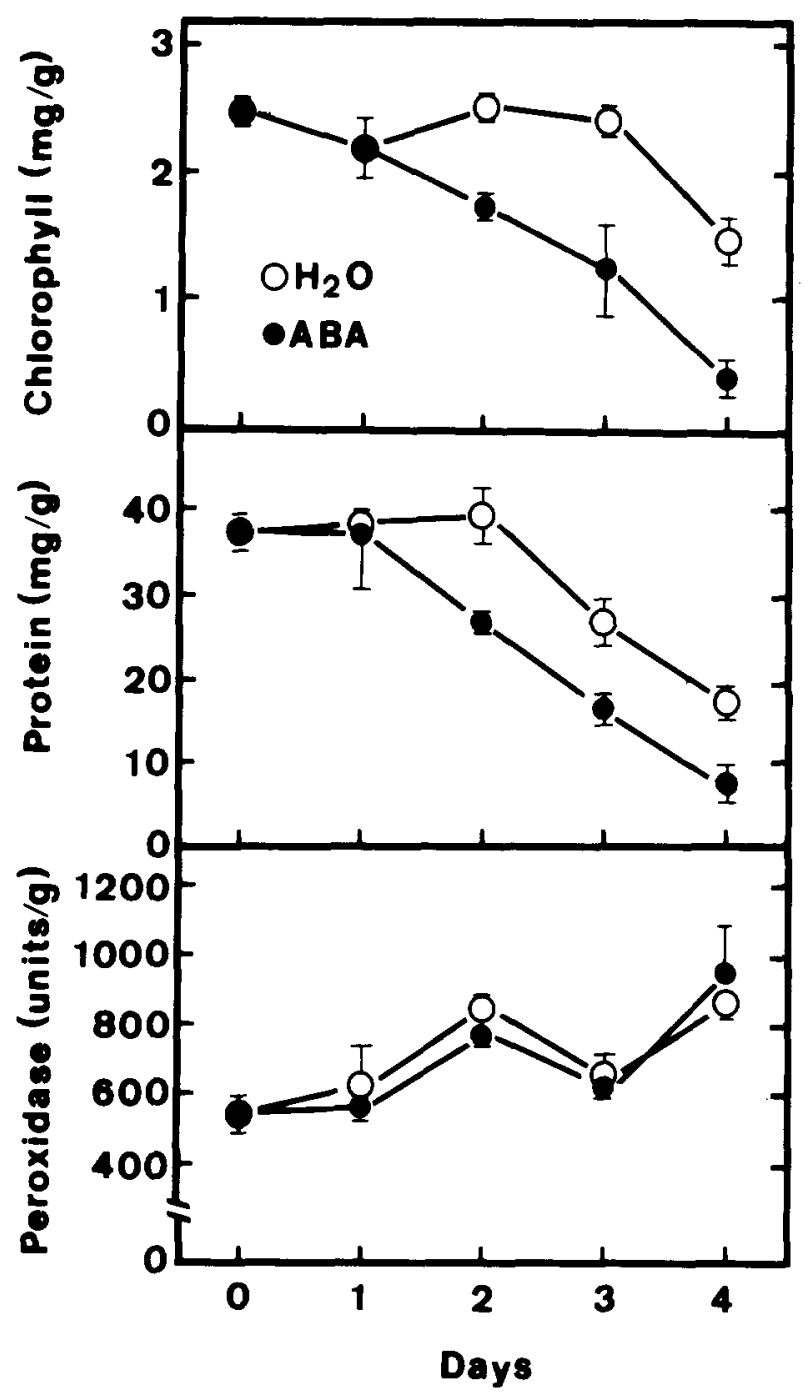

Fig. 3. Effects of ABA on chlorophyll and protein levels and peroxidase activity of detached rice leaves (cv. Tainung 67). Detached rice leaves were treated with $45 \mu \mathrm{M}$ ABA under dark conditions. Bars indicate standard errors $(n=4)$. Only those standard errors larger than the symbol are shown.

was found to inhibit ethylene production by rice seedlings in a concentration-dependent manner. $\mathrm{MJ}$ also inhibited ethylene production but to a lesser extent.

\section{Induction of Callus from Rice Anthers}

Ravnikar and Gogala (1990) demonstrated that jasmonic acid inhibited callus induction from potato meristems. This is the only report dealing with the effects of jasmonates on callus induction. In the present investigation, we examined the effect of $\mathrm{MJ}$ and $\mathrm{ABA}$ on callus induction from anthers of rice 


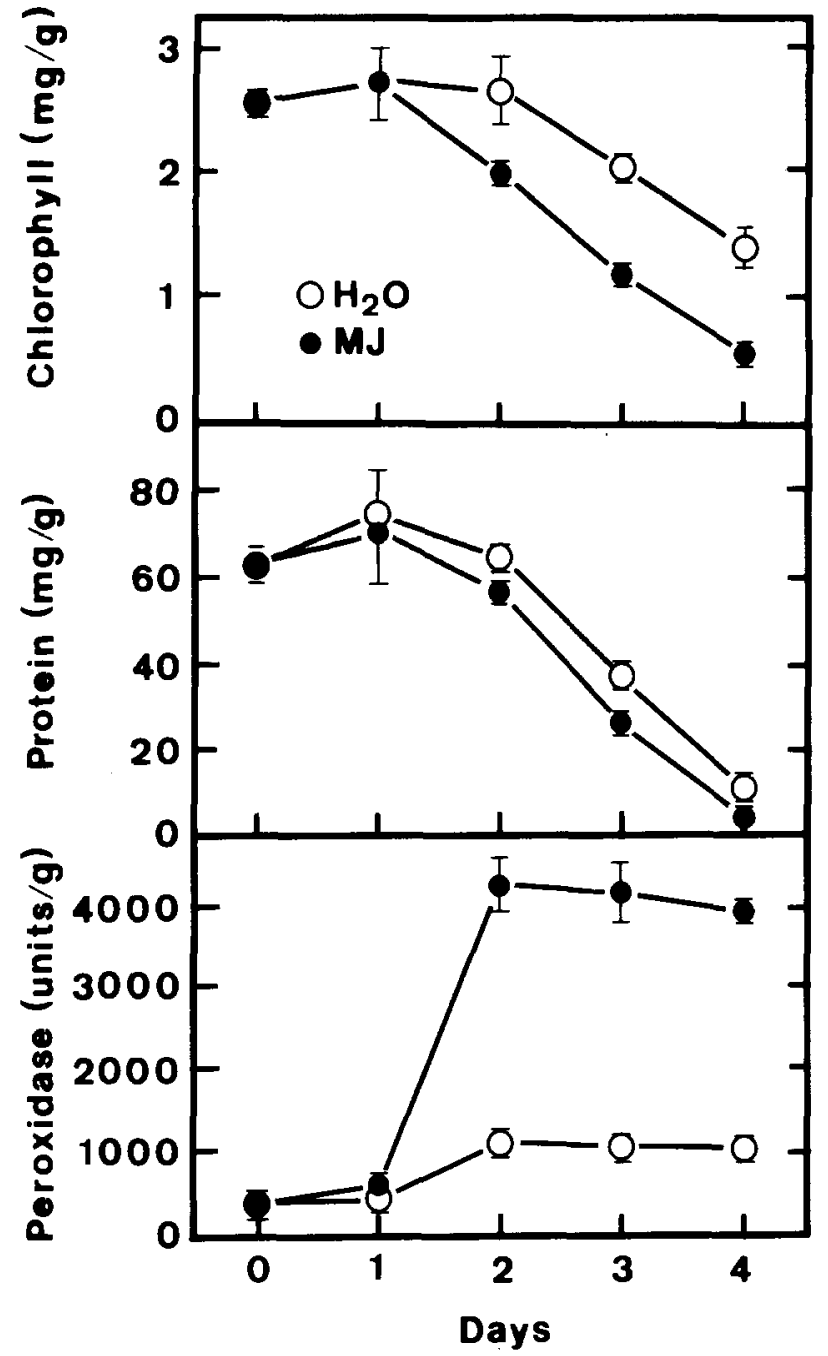

Fig. 4. Effects of MJ on chlorophyll and protein levels and peroxidase activity of detached rice leaves (cv. Tainung 67). Detached rice leaves were treated with $45 \mu \mathrm{M}$ MJ under dark conditions. Bars indicate standard errors $(n=4)$. Only those standard errors larger than the symbol are shown.

(Table 1). MJ significantly inhibited callus formation. However, ABA was found to be less effective in inhibiting callus formation. ABA inhibited callus formation only at a high concentration $(112.5 \mu \mathrm{M})$. At a low concentration $(4.5 \mu \mathrm{M}), \mathrm{ABA}$, in contrast, slightly promoted callus formation.

\section{Regeneration of Callus Derived from Anthers}

The effects of $\mathrm{MJ}$ and $\mathrm{ABA}$ on the regeneration ability of anther-derived callus were also compared (Table 2). MJ inhibited the regeneration ability (percent of callus producing green seedlings). Increasing the MJ concentration from 2.25 to $225 \mu \mathrm{M}$ progressively inhibited the regeneration ability of cal-

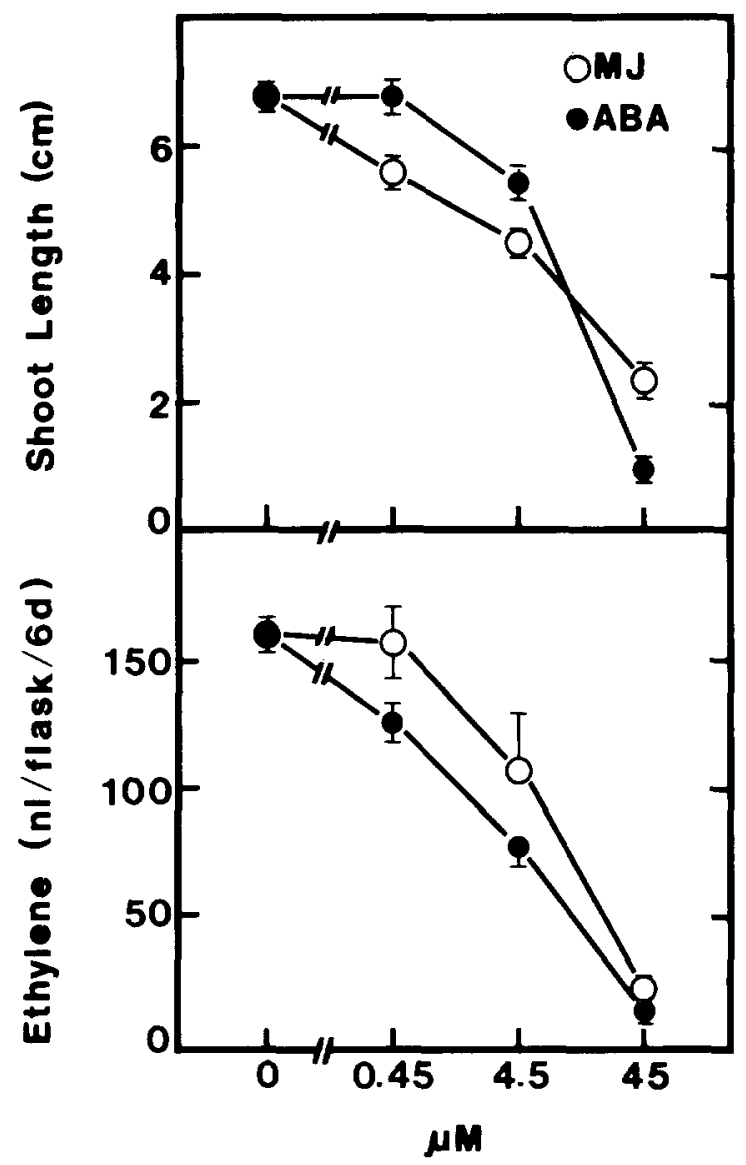

Fig. 5. Effects of $M J$ and $A B A$ on shoot growth and ethylene production of rice seedlings (cv. Taichung Native 1). Germinated seeds were treated with various concentrations of MJ and ABA in a sealed flask under dark conditions. Shoot length and ethylene production were measured at 6 days after treatment. Bars indicate standard errors $(n=4)$.

Table 1. Effects of MJ and ABA on the induction of callus from anthers of rice (cv. Tainung 67). Callus was induced in NK medium, and callus produced was counted at 60 days after inoculation of anthers. Data in parentheses are the $95 \%$ confidence limits of binomial variation.

\begin{tabular}{clc}
$\begin{array}{l}\text { Concentration } \\
(\mu \mathrm{M})\end{array}$ & $\begin{array}{l}\text { No. of anthers } \\
\text { cultured }\end{array}$ & $\begin{array}{l}\text { Anthers producing } \\
\text { callus }(\%)\end{array}$ \\
\hline MJ & & \\
0 & 515 & $52(47-57)$ \\
4.5 & 953 & $15(13-17)$ \\
112.5 & 987 & $1(0-2)$ \\
ABA & & \\
0 & 826 & $56(53-59)$ \\
4.5 & 660 & $61(57-65)$ \\
112.5 & 919 & $36(33-39)$ \\
\hline
\end{tabular}

lus. In contrast, ABA did not affect regeneration ability at all. No inhibition of the regeneration ability of anther-derived callus was observed even at the highest concentration $(225 \mu \mathrm{M})$. 
Table 2. Effects of MJ and ABA on the regeneration ability of anther-derived callus of rice (cv. Tainung 67). Ten-day-old callus derived from anthers in the absence of $\mathrm{ABA}$ and $\mathrm{MJ}$ was subcultured in NK medium containing various concentrations of $\mathrm{MJ}$ and ABA for 7 days and then transferred to R-2 medium under light conditions for regeneration. After 4 weeks in R-2 medium, calli producing greening seedlings were recorded. Data in parentheses are the $95 \%$ confidence limits of binomial variation.

\begin{tabular}{cll}
\hline $\begin{array}{l}\text { Concentration } \\
(\mu \mathrm{M})\end{array}$ & $\begin{array}{l}\text { No. of calli in } \\
\text { regeneration medium }\end{array}$ & $\begin{array}{l}\text { Calli producing } \\
\text { green seedlings } \\
(\%)\end{array}$ \\
\hline MJ & & \\
0 & 120 & $8(4-15)$ \\
2.25 & 116 & $8(4-15)$ \\
4.5 & 112 & $5(2-11)$ \\
22.5 & 112 & $3(1-8)$ \\
45.0 & 116 & $3(0-4)$ \\
225 & 120 & $0(0-4)$ \\
ABA & & $8(4-15)$ \\
0 & 112 & $9(4-16)$ \\
2.25 & 112 & $8(4-15)$ \\
4.5 & 108 & $8(4-15)$ \\
22.5 & 106 & $9(4-16)$ \\
45 & 100 & $7(3-14)$ \\
225 & 104 & \\
\hline
\end{tabular}

\section{Discussion}

The effects of MJ and ABA on some physiological processes of rice were compared in the present investigation. Although it has been claimed that jasmonates have both chemical and physiological similarities to ABA (Anderson et al. 1989), our results demonstrated that not all physiological effects were similar to those of ABA. MJ and ABA were found to have opposite effects on ACC-dependent ethylene production in detached rice leaves. MJ promoted ACC-dependent ethylene production, whereas $\mathrm{ABA}$ inhibited it. $\mathrm{MJ}$ and $\mathrm{ABA}$ were also found to affect differentially the regeneration ability of anther-derived callus. The regeneration ability of anther-derived callus was inhibited by MJ but not by ABA. Similar results were obtained in the induction of peroxidase activity in senescing detached rice leaves. It is MJ rather than ABA which markedly induces peroxidase activity.

The important finding of the present investigation is that MJ markedly induced Apase activity in detached rice leaves. This is the first evidence that MJ induced Apase activity in leaf tissues. The induction of Apase in phosphorus-deficient plants is a ubiquitous phenomenon. The increased activity of Apase correlated well with a low level of phosphorus in leaf tissues (Barrett-Lennard and Greenway 1982, Besford and Syred 1979, O'Cornnell and Grove 1985, Szabo-Nagy et al. 1992). However, the induction of Apase activity by MJ was not revers- ible by the addition of orthophosphate (data not shown), making it very unlikely that the MJinduced increase in Apase activity is because of a decrease in the level of phosphorus. It has also been reported that drought induced an increase in Apase activity without exerting significant changes in the phosphorus level (Barrett-Lennard et al. 1982). No loss of turgidity was visually observed in $\mathrm{MJ}$ treated rice leaf segments. In contrast, there was a slight but significant increase in the fresh weight of rice leaf segments floated on MJ solution, possibly because of the closure of stomata (data not shown). Thus the increase in Apase activity in MJ-treated rice leaf segments is unlikely to have been caused by water deficit. Further experiments are required to elucidate the mechanism for the marked MJinduced increase in Apase activity in detached rice leaves.

MJ has been shown to promote leaf senescence in a range of graminaceous species (Ueda and Kato 1981, Weidhase et al. 1987). We also observed that MJ was effective in promoting the senescence of detached rice leaves. Increased peroxidase activity has been proposed to act as a senescence-inducing enzyme (Parish 1968). The senescence of detached rice leaves was promoted by both $\mathrm{MJ}$ and $\mathrm{ABA}$. However, MJ but not ABA was found to increase peroxidase activity markedly when compared with the water control. These data indicate that the role of peroxidase on the senescence of detached rice leaves cannot be considered in terms of total activity alone. However, an anionic isoperoxidase having $R_{F} 0.74$ was observed to be promoted by $\mathrm{MJ}$ and ABA (Yeh and Kao 1994).

It is well established that ethylene plays an important role in rice coleoptile elongation $(\mathrm{Ku}$ et al. 1970). Thus it is of interest to know whether the inhibition of ethylene production by $\mathrm{MJ}$ and $\mathrm{ABA}$ observed in rice seedlings was causally related to the inhibition phenomenon of shoot growth or was a process independent of growth. The latter alternative was favored from our results, since $\mathrm{MJ}$ inhibited shoot growth at a concentration $(0.45 \mu \mathrm{M})$ that did not alter ethylene production, and $\mathrm{ABA}$ at a concentration as low as $0.45 \mu \mathrm{M}$ was effective in inhibiting ethylene production but did not alter shoot growth.

\section{References}

Anderson JM, Spilatro SR, Klauer SF, Franceschi VR (1989) Jasmonic acid-dependent increase in the level of vegetative storage proteins in soybean. Plant Sci 62:45-52

Barrett-Lennard EG, Greenway H (1982) Partial separation and characterization of soluble phosphatases from leaves of wheat grown under phosphorus deficiency and water deficit. J Exp Bot 33:694-704 
Barrett-Lennard EG, Robson AD, Greenway H (1982) Effect of phosphorus deficiency and water deficit on phosphatase activities from wheat leaves. J Exp Bot 33:682-693

Besford RT, Syred AD (1979) Effect of phosphorus nutrition on the cellular distribution of acid phosphatase in the leaves of Lycopersicon esculentum L. Ann Bot 43:431-435

Chen CT, Kao CH (1991) Senescence of rice leaves. XXX. Levels of endogenous polyamines and dark-induced senescence of rice leaves. Plant Cell Physiol 32:935-941

Chen CT, Kao CH (1993) Osmotic stress and water stress have opposite effects on putrescine and proline production in excised rice leaves. Plant Growth Regul 13:197-202

Chen CT, Chou CM, Kao CH (1994) Methyl jasmonate induces the accumulation of putrescine but not proline in detached rice leaves. J Plant Physiol 143:119-121

Chou CM, Kao CH (1992) Stimulation of 1-aminocyclopropane1-carboxylic acid-dependent ethylene production in detached rice leaves by methyl jasmonate. Plant Sci 83:137141

Chu CC, Wang CC, Sun SC, Chen H, Yin KC, Chu CY, Bi FY (1975) Establishment of an efficient medium for anther culture of rice through comparative experiments on the nitrogen sources. Sci Sin 17:657-668

Creelman RA (1989) Abscisic acid physiology and biosynthesis in higher plants. Physiol Plant 75:131-136

Huang Y, Kao CH (1991) Senescence of rice leaves. XXV. Changes of acid phosphatase activity. Bot Bull Acad Sin $32: 37-42$

Hurng WP, Kao CH (1994) Effect of flooding on the activities of some enzymes of activated metabolism, the level of antioxidants, and lipid peroxidation in senescing tobacco leaves. Plant Growth Regul 14:34-44

Kao CH (1980) Senescence of rice leaves. IV. Influence of benzyladenine on chlorophyll degradation. Plant Cell Physiol 21:1255-1262

Kao CH, Yang SF (1982) Light inhibition of the conversion of 1-aminocyclopropane-1-carboxylic acid to ethylene in leaves is mediated through carbon dioxide. Planta 155: 261-266
Ku HS, Suge H, Rappaport L, Pratt HK (1970) Stimulation of rice coleoptile growth by ethylene. Planta 90:333-339

Murashige T, Skoog F (1962) A revised medium for rapid growth and bioassays with tobacco tissue culture. Physiol Plant 15:473-497

O'Cornnell AM, Grove TS (1985) Acid phosphatase activity in karri (Eucalyptus diversicolor F. Muell) in relation to soil phosphate and nitrogen supply. J Exp Bot 36:1359-1372

Parish RW (1968) Studies on senescing tobacco leaf disks with special reference to peroxidase. I. The effects of cutting and inhibitors of nucleic acid and protein synthesis. Planta 82:1-13

Raskin I, Kende H (1983) Regulation of growth in rice seedlings. J Plant Growth Regul 2:193-203

Ravnikar M, Gogala N (1990) Regulation of potato meristem development by jasmonic acid in vitro. J Plant Growth Regul 9:233-236

Sembdner G, and Parthier B (1993) The biochemistry and the physiological and molecular actions of jasmonates. Annu Rev Plant Physiol Plant Mol Biol 44:569-589

Szabo-Nagy A, Galiba G, Drdei L (1992) Induction of soluble phosphatases under ionic and nonionic osmotic stress in wheat. J Plant Physiol 140:629-633

Turner FT, Chen CC, McCauley GN (1981) Morphological development of rice seedlings in water of controlled oxygen levels. Agron J 73:566-570

Ueda J, Kato J (1981) Promotive effect of methyl jasmonate on oat leaf senescence in the light. Z Pflanzenphysiol 103: 357-359

Weidhase RA, Lehmann J, Kramell H, Sembdner G, Parthier B (1987) Degradation of ribulose-1,5-bisphosphate carboxylase and chlorophyll in senescing barley leaf segments triggered by jasmonic acid methylester, and counteraction by cytokinin. Physiol Plant 69:161-166

Wen SC, Chuang CH, Yeh CC, Tsay HS (1992) Effect of agarand sugar-induced water stress on rice anther culture. Chin Agron J 2:69-81

Yeh JH, Kao CH (1994) Senescence of rice leaves. XXXIII. Changes in peroxidase activity and in peroxidase isozymes. Bot Bull Acad Sin 35:205-209 